\title{
Ras/MEK But Not p38 Signaling Mediates NT-3-Induced Neurite Extension from Spiral Ganglion Neurons
}

\author{
Christoph Aletsee, ${ }^{1,2}$ Andrew Beros, ${ }^{1}$ Lina Mullen, ${ }^{1}$ Sean Palacios, ${ }^{1}$ Kwang Pak, ${ }^{1}$ \\ STEFAN DAZERT, ${ }^{2}$ AND Allen F. RYAN ${ }^{1}$ \\ ${ }^{1}$ Department of Surgery/Otolaryngology and Neurosciences, UCSD School of Medicine and VA Medical Center, \\ La Jolla, CA 92093, USA \\ ${ }^{2}$ Department of Otolaryngology-Head and Neck Surgery, Bayerische Julius-Maximilians-Universität, \\ 97080 Würzburg, Germany
}

Received: 30 October 2000; Accepted: 12 April 2001; Online publication: 31 August 2001

\begin{abstract}
Neurotrophin (NT)-3 is expressed in the neuronal target tissue of the developing rat cochlea and has been shown to promote the survival and neurite outgrowth of spiral ganglion (SG) neurons, suggesting a role for this protein during the innervation of the organ of Corti. In other neurons, NT-3 can mediate neuritogenesis and survival via a number of intracellular signal pathways. To date, the intracellular transduction pathways involved in the mediation of NT-3 effects have not been investigated in SG neurons. To determine whether the activities of NT-3 on SG neurons are dependent on the activation of mitogen-activated protein kinase kinases (MEK) / extracellular-signal-regulated kinases (ERK), Ras, and/or p38, SG explants from postnatal-day 4 rats were cultured with NT-3 and increasing concentrations of the MEK inhibitor U0126, the Ras farnesyl-transferase inhibitor (FTI)277, and the p38 inhibitor SB203580. After fixation and immunocytochemical labeling, neurite growth was evaluated. A dose-dependent decrease of the effects of NT-3 on length and number of processes was observed in the U0126- and FTI-277-treated SG neurons. In contrast, SB203580 had no significant effect on NT-3-mediated stimulation of neurite growth, in terms of either number or length. The results suggest that NT-3 effects on SG neurons are mediated primarily by the Ras/MEK/ERK signaling pathway.
\end{abstract}

Correspondence to: Allen F. Ryan, Ph.D. - UCSD-School of Medicine - 9500 Gilmann Drive, \#0666 • La Jolla, CA 92093. Telephone: (858) 534-4594; fax: (858) 534-5319; email: afryan@ucsd.edu
Keywords: MEK, Ras, p38, spiral ganglion, development, rat

\section{INTRODUCTION}

Neurotrophin (NT)-3 is expressed in the neuronal target tissues of the developing rat spiral ganglion (SG) cells (Pirvola et al. 1992) and promotes the survival and neurite outgrowth of SG neurons in vitro (e.g., Staecker et al. 1996). These findings suggest a role for this protein during the innervation process of the organ of Corti. The observation that NT-3 knockout mice show an $85 \%$ decrease of SG neuron population (Farinas et al. 1994) further supports the trophic activities of this peptide on SG neurons. To date, the intracellular signal transduction pathways involved in the mediation of NT-3 effects have not been investigated in SG neurons.

In other systems, most specific neurotrophin signaling effects result from stimulation of the high-affinity tyrosine kinase receptors (trks) (Sutter et al. 1979) trkA, trkB, and trkC (Chao 1992). TrkC, the functional receptor for NT-3 (Lamballe et al. 1991), has been localized to SG neurons (Merlio et al. 1992) but not to glial cells and fibroblasts within the SG (Pirvola et al. 1994). Among multiple signal transduction pathways that can be activated by the phosphosylation of the trk receptor, the cascades implicated in coupling neurotrophin signals to the cell nucleus are the mitogen-activated protein kinases (MAPKs) (Kaplan and 


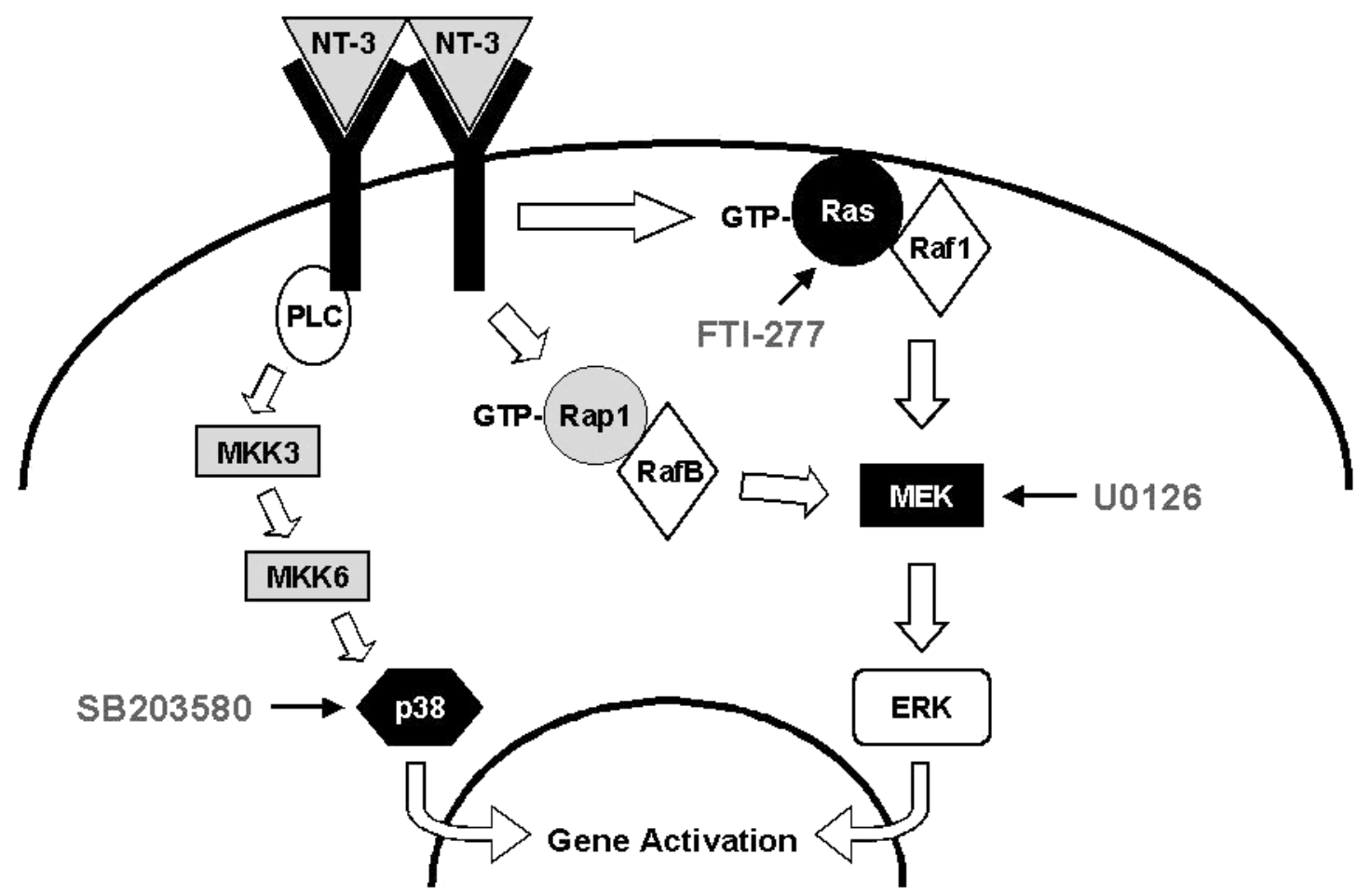

FIG. 1. Simplified signaling pathways linking trk receptors to the nucleus via Ras, MEK, and $\mathrm{p} 38$. The sites of action of the inhibitors used in this study are indicated.

Miller 2000). Three MAPK cascades-the extracellular-signal-regulated kinases (ERKs) (Boulton et al. 1991), the c-jun N-terminal kinases (JNK) (Kyriakis et al. 1994), and the p38 pathway (Rouse et al. 1994) have been described in mammalian cells.

In pheochromocytoma (PC)-12 cells, neurotrophins have been shown to stimulate the sustained activation of the ERKs, inducing neuronal differentiation and neurite outgrowth (Boulton et al. 1991; Marshall 1995). ERKs 1 and 2 have been shown to be activated by the MAP kinase kinase (MEK) (Crews and Erikson 1992), but the regulation of MEK/ERK core signaling modules by upstream components is not completely understood. Ras, a small guanine-binding $(G)$ protein upstream of MEK, has been suggested to play a central role in signal transduction from trk to the cell nucleus by activating MEK through Raf (Lange-Carter and Johnson 1994). Recently however, it has been found that the sustained activation of ERKs induced by neurotrophins can occur independent of Ras activation in PC12 cells (York et al. 1998). This suggests that other signaling pathways may be involved in the neurotrophin-regulated neurite outgrowth (Fig. 1).

The p38 MAPK family of enzymes has not been investigated as intensely as the ERK pathway. Iwasaki et al. (1999) demonstrated that the neurite outgrowthinducing effect of bone morphogenic protein-2 on PC12 cells occurs without marked activation of ERKs and can be inhibited by the p38 inhibitor SB203580.
Other investigators have shown that p38 is activated after stimulation of cerebellar granule cells (Morooka and Nishida 1998) and hippocampus cells (Blanquet 2000) with the neurotrophin brain-derived neurotrophic factor, suggesting that this pathway may be involved in the mediation of neurotrophin/trk signaling (Fig. 1).

The purpose of the present study was to investigate whether the effects of NT-3 on whole explants of SG neurons are dependent upon the activation of MEK, Ras, and/or p38.

\section{MATERIALS AND METHODS}

\section{Preparation of the tissue culture}

Twenty-four well tissue culture plates (Costar, Acton, MA, USA) were incubated with poly-L-lysine $(1 \mathrm{mg} /$ $\mathrm{mL}$ ) in Dulbeccos modified eagle medium at $37^{\circ} \mathrm{C}$ for $1 \mathrm{~h}$, washed with a $10 \mathrm{X}$ volume of phosphate-buffered saline (PBS), and then coated with $10 \mu \mathrm{g} / \mathrm{mL}$ fibronectin from human plasma (Sigma-Aldrich, St. Louis, MO, USA) in PBS at $4^{\circ} \mathrm{C}$ overnight. After rinsing the well with two 10X volumes of PBS immediately prior to the dissection, the wells were filled with a primary growth media consisting of Dulbeccos modified eagle medium with $10 \%$ fetal bovine serum, $25 \mathrm{mM}$ HEPES buffer, 


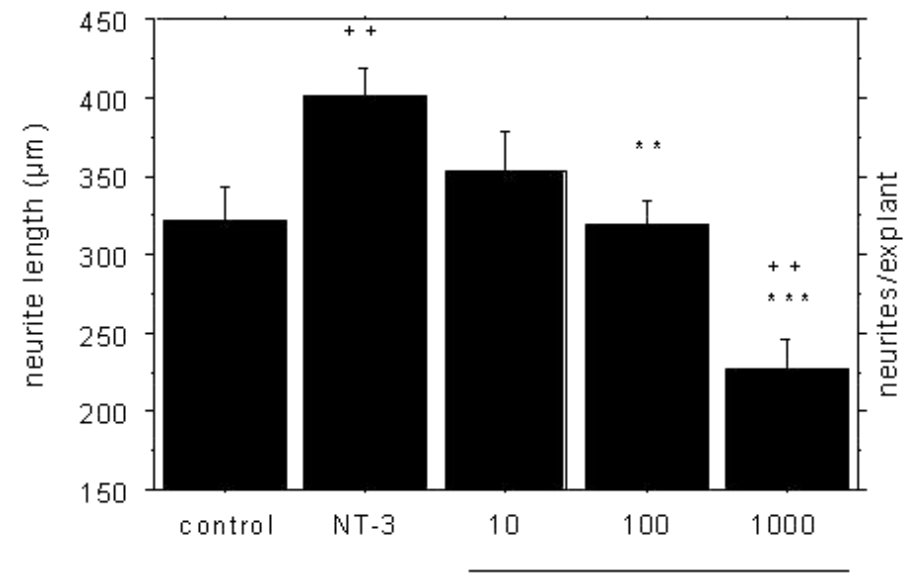

$N T-3(25 n g / m l)+U 0126(n M)$

FIG. 2. Chart illustrating the effects of MEK inhibition on the average length (left) and number (right) of neurites extending from SG explants incubated with NT-3. Control explants were grown in unsupplemented media. All other explants were incubated with $25 \mathrm{ng} / \mathrm{mL}$ NT-3 and treated with different concentrations of the MEK inhibitor U0126. MEK inhibition significantly reduced the NT-3-related increase in neurite length and number. The highest dosage of U0126

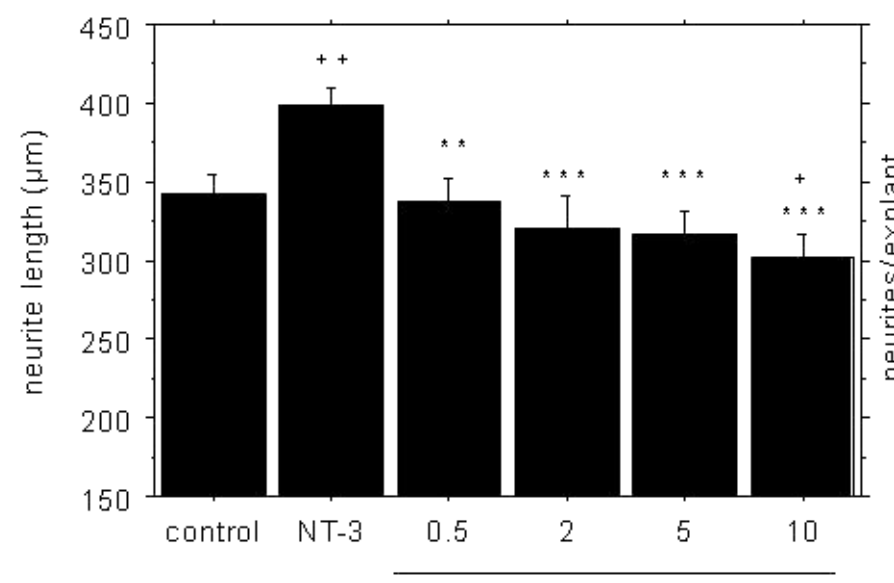

NT-3(25ng/ml) $+\mathrm{FTl}-277(\mu \mathrm{M})$

FIG. 3. Effects of Ras inhibition on the average length (left) and number (right) of neurites extending from NT-3-exposed SG explants. Control explants were grown in unsupplemented media. All other explants were incubated with $25 \mathrm{ng} / \mathrm{mL}$ NT-3 and treated with different concentrations of the Ras farnesylation inhibitor FTI-277. Ras inhibition significantly decreased NT-3-related enhancement of neurite length and of neurite number, up to $5 \mu \mathrm{M}$. The highest dosage of FTI-277 decreased neurite length below that of control explants.

and $300 \mathrm{U} / \mathrm{mL}$ penicillin and stored at $37^{\circ} \mathrm{C}, 5 \% \mathrm{CO}_{2}$, and $95 \%$ humidity.

\section{Dissection of SG explants}

The surgical procedures were approved by the local animal subject committee (La Jolla, CA, USA) in accordance with the guidelines laid down by NIH regarding

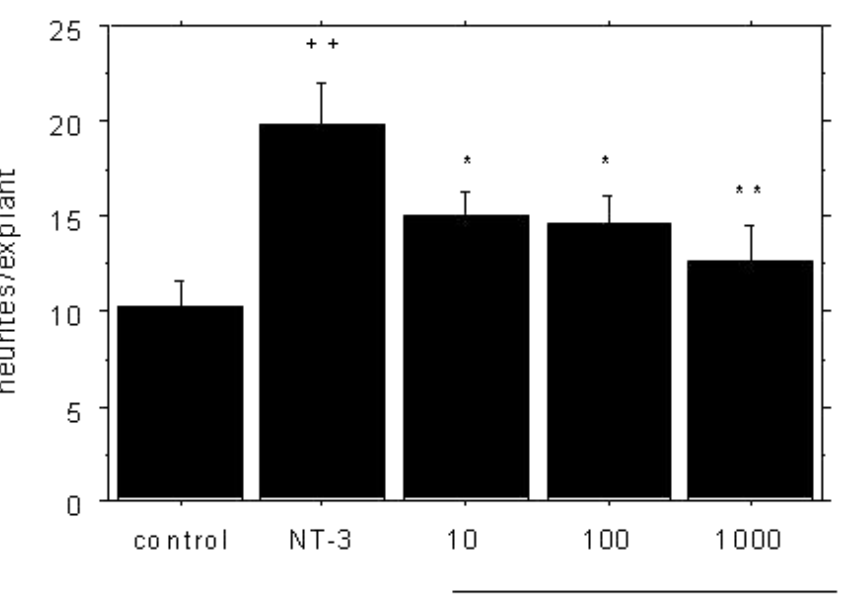

NT-3 $(25 \mathrm{ng} / \mathrm{ml})+\mathrm{U} 0126(\mathrm{nM})$

decreased neurite length even below that of control explants not treated with NT-3. Vertical lines represent one standard error. The length axis has been truncated to compensate for neurite growth that occurred before explants were cultured in the experimental media. $*$ = significantly different than NT-3 treated samples. $+=$ significantly different than control (nontreated) samples. + and $*=p<0.05$, ++ and $^{* *}=p<0.01 ;+++$ and $* * *=p<0.001$.

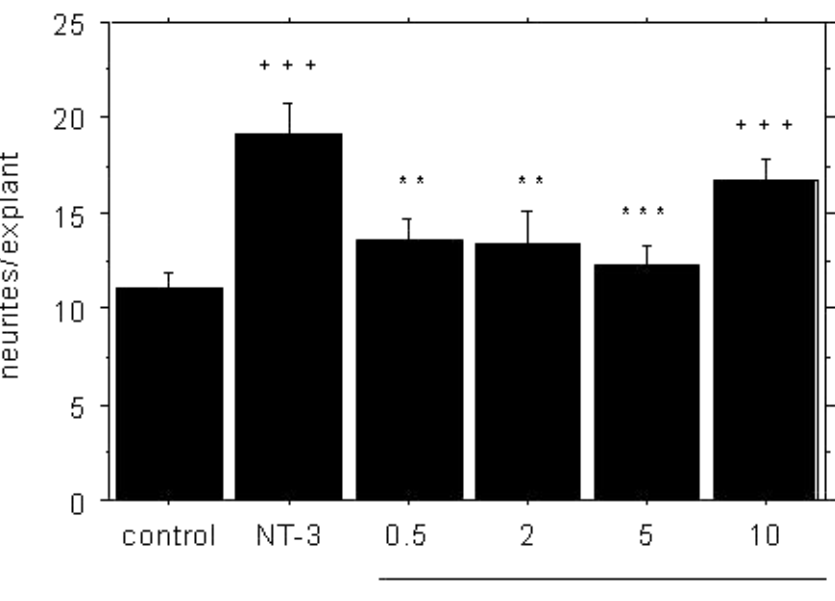

NT-3(25ng/ml) $+\mathrm{FTI}-277(\mu \mathrm{M})$

However, the reduction NT-3-induced increase in neurite number seen at lower FTI-277 dosages was not observed at the highest dosage. Vertical lines represent one standard error. The length axis has been truncated to compensate for neurite growth that occurred before explants were cultured in the experimental media. ${ }^{*}=$ significantly different than NT-3 treated samples. $+=$ significantly different than control (nontreated) samples. + and $*=p<0.05,++$ and $* *=$ $p<0.01 ;+++$ and ${ }^{* * *}=p<0.001$.

the care and use of animals for experimental procedures. Postnatal-day-4 Sprague-Dawley rat SGs were harvested as described by Van de Water (1971), with slight modifications. The rats were anesthetized with an intraperitoneal injection of a rodent cocktail (ketamine $1.26 \mathrm{mg} / \mathrm{mL}$, acepromezine $0.25 \mathrm{mg} / \mathrm{mL}$, Rompun $1.26 \mathrm{mg} / \mathrm{mL}) 0.4 \mathrm{~mL}$ per $100 \mathrm{~g}$ body weight and transected cervically. Under sterile conditions, the ani- 


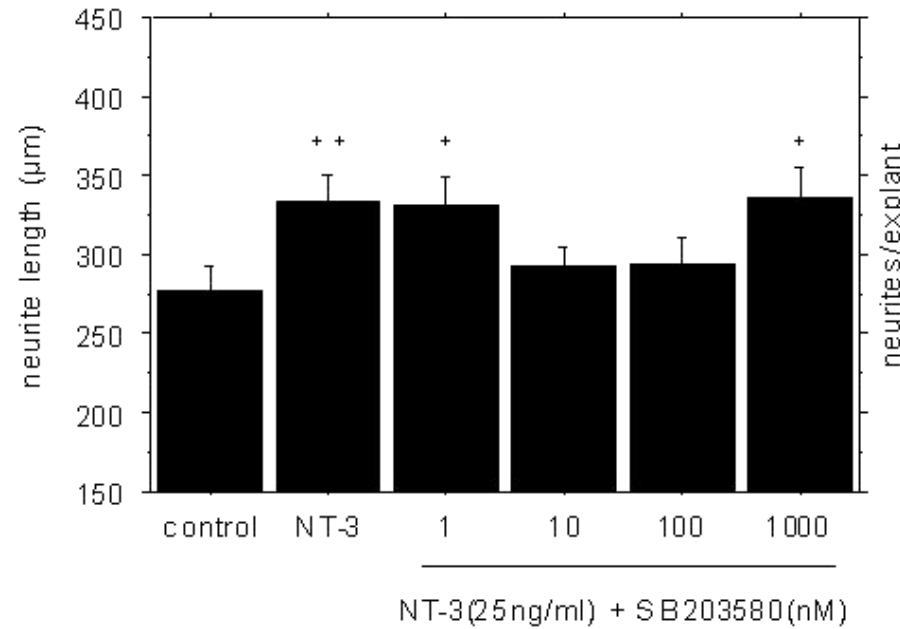

FIG. 4. Effects of p38 inhibition on the length (left) and number (right) of neurites extending from SG explants exposed to NT-3. Control explants were grown in unsupplemented media. All other explants were incubated with $25 \mathrm{ng} / \mathrm{mL}$ NT-3 and treated with different concentrations of the p38 inhibitor SB203580. p38 inhibition did not significantly affect NT-3-related increase in neurite length and num-

mal skulls were then opened midsagitally. Following the identification of the temporal bone, the membranous labyrinth was exposed by peeling off the cartilaginous cochlear capsule under a dissecting microscope. The SG was dissected from the modiolus after the removal of the stria vasularis and the organ of Corti and cut into 8-10 approximately equal portions.

\section{Tissue culture}

Following the dissection, the SG explants were immediately transferred into the culture well filled with the primary growth medium. The explants remained in the primary growth medium overnight to promote attachment. The first medium was substituted by a serum-free maintenance growth medium consisting of Dulbeccos modified eagle medium, $30 \mu \mathrm{L} / \mathrm{mL}$ N2 supplement, $6 \mathrm{mg} / \mathrm{mL}$ glucose, $25 \mathrm{mM}$ HEPES, and $300 \mathrm{U} / \mathrm{mL}$ penicillin after attachment of the explants.

The explants of the first experimental group were grown in maintenance growth medium supplemented with $25 \mathrm{ng} / \mathrm{mL}$ NT-3 (Upstate, Lake Placid, NY, USA) and treated with 1000,100 , or $10 \mathrm{nM}$ of the MEK inhibitor U0126 (Calbiochem, San Diego, CA, USA) with the penetrant dimethyl sulfoxide (DMSO) (Sigma-Aldrich). Between 9 and 11 explants were evaluated for every condition investigated, in one experiment. As a control to evaluate the effects of U0126 on SG cells cultured without NT-3, explants were grown in maintenance growth medium alone and coincubated with the MEK inhibitor U0126 $(1000,100$, or $10 \mathrm{nM})$ with DMSO. Between 9 and 10 explants were evaluated for every condition investigated in a separate experiment.

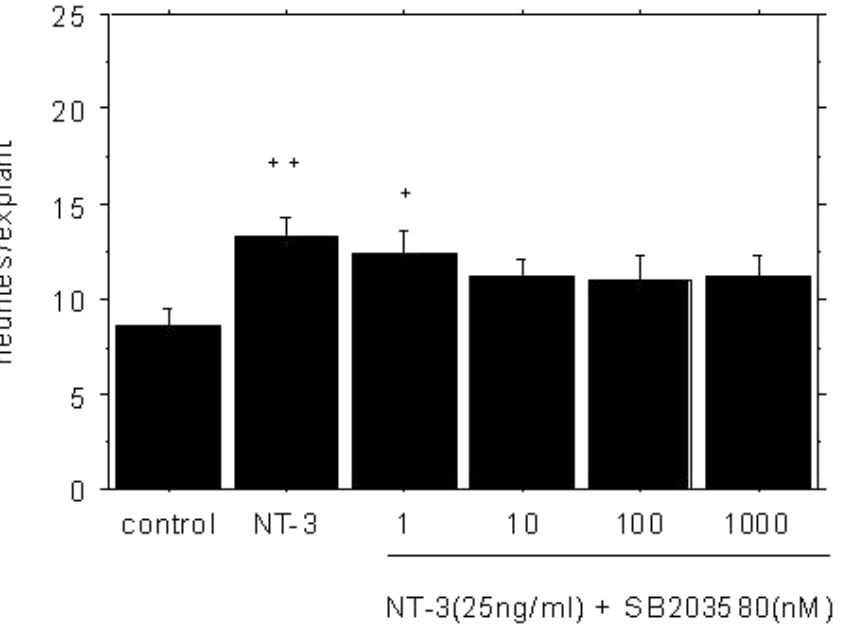

ber. Vertical lines represent one standard error. The length axis has been truncated to compensate for neurite growth that occurred before explants were cultured in the experimental media. ${ }^{*}=$ significantly different than NT-3 treated samples. $+=$ significantly different than control (nontreated) samples. + and $*=p<0.05 ;++$ and ${ }^{* *}=$ $p<0.01 ;+++$ and ${ }^{* * *}=p<0.001$.

The explants of the second group were cultured in maintenance growth medium supplemented with 25 $\mathrm{ng} / \mathrm{mL}$ NT-3 and treated with increasing concentrations $(0.5,2,5$, or $10 \mu \mathrm{M})$ of the Ras inhibitor FTI277 (Calbiochem) with DMSO. Between 18 and 36 explants were analyzed for every condition investigated, in two experiments. As a control, explants were grown in maintenance growth medium alone and treated with the Ras inhibitor FTI-277 $(10,5,2$, or 0.5 $\mu \mathrm{M})$ with DMSO. Between 18 and 21 explants were analyzed for every condition investigated in two experiments.

The samples of the third group were grown in maintenance growth medium supplemented with NT-3 (25 $\mathrm{ng} / \mathrm{mL}$ ) and $1000,100,10$, or $1 \mathrm{nM}$ of the p38 inhibitor SB203580 (Calbiochem) with DMSO. A total of 17-20 samples were included in every group studied in two experiments. As a control, eight samples were grown in maintenance growth medium alone and treated with p38 inhibitor SB203580 (1000 nM) with DMSO in one experiment.

To investigate any potential effect of DMSO, nonNT-3-treated explants were incubated in the presence of $0.1 \%$ DMSO, the highest concentration of this substance used in this study, and compared with non-NT3-treated control explants. Thirty to 36 explants were analyzed in two experiments. Additionally, explants grown in maintenance growth medium supplemented with NT-3 $(25 \mathrm{ng} / \mathrm{mL})$ and, as an additional negative control for the MEK inhibitor U0126, explants treated with NT-3 (25 ng/mL) and $1000 \mathrm{nM} \mathrm{U0124} \mathrm{(Calbio-}$ chem) were incubated in the presence of $0.1 \%$ DMSO and compared with NT-3-treated explants. Seven to 8 explants were analyzed in one experiment. 
All samples were cultured under their specific conditions for $48 \mathrm{~h}$ at $37^{\circ} \mathrm{C}, 5 \% \mathrm{CO}_{2}$, and $95 \%$ humidity. The second media for all experiments was renewed at $24 \mathrm{~h}$.

After three days in culture, two control SG explants and two explants treated with the highest dosage of each inhibitor were coincubated with trypan blue for 5 min to evaluate viability of the neurites and possible toxic effects of the substances utilized.

\section{Fixation and immunohistochemistry}

The explants were fixed with $4 \%$ paraformaldehyde for $15 \mathrm{~min}$ and washed with phosphate-buffered saline following cell culture. By incubating the samples with $1 \%$ donkey serum (Sigma-Aldrich) for $10 \mathrm{~min}$ at room temperature, nonspecific antibody binding was reduced. In order to detect $200-\mathrm{kDa}$ neurofilament, the specimens were incubated with a polyclonal antineurofilament antibody (Sigma-Aldrich) developed in rabbit and diluted 1:500 in 1\% donkey serum at $4^{\circ} \mathrm{C}$ overnight. The explants were then incubated for $2.5 \mathrm{~h}$ at room temperature with Texas red- or fluorescein (FITC)-conjugated donkey antirabbit secondary antibody (Jackson Immuno Research, West Grove, PA, USA) diluted 1:100 in 1\% donkey serum. Immunolabeling controls, in which the primary antibody was eliminated, exhibited no labeling.

\section{Quantitation of neurite growth}

The explants were photographed under an inverted microscope equipped with appropriate excitation/ emission filters (Texas red: 592/618, fluorescein (FITC): 448/509). For illustrations, images were modified with Adobe Photoshop ${ }^{\circledR} 5.0$ (Adobe, San Jose, CA, USA) when necessary to match color, contrast, and brightness. Neurite outgrowth from the ganglia was evaluated in terms of number and length of the processes stained positive for neurofilament. For every explant the length of the neurites was determined by measuring the linear distance from the ganglion edge to the central body of the growth cone of the five longest processes and taking the average. The five longest neurites were selected because this number was present on all samples, even those with few processes. As SG neurons are polarized, explants commonly show a restricted area of neurite outgrowth and typically the numbers of processes extending from different areas of the explant edge were asymmetrical. To reduce the effects of this asymmetry, which would have overstated the effects of number enhancement for some explants and also increased variability, the quadrant with the most neurites was identified, and the number of neurites in this quadrant was counted as a measure of the number of outgrowing processes. The groups were compared statistically by ANOVA.

\section{RESULTS}

\section{Morphological appearance of the explants}

Growth of neurites from SG explants was similar to that described previously (e.g., Lefebvre et al. 1992; Dazert et al. 1998). Processes generally extended from the explant in a radial direction, although typically the number of processes extending from different areas of the explant edge was not equal. The neurites commonly grew as bundles close to the explant edge, dividing into individual processes as distance from the explant increased. The processes tended to avoid each other and crossing of neurites was seldom observed. The extension of supporting cells, such as glial cells and fibroblasts, from the explant was concurrent with neurite outgrowth (Figs. 5-10).

\section{Treatment with NT-3}

The neurite outgrowth of the experimental SG explants cultured in the presence of NT-3 $(25 \mathrm{ng} / \mathrm{mL})$ showed a significant increase in terms of both length $(p<0.01)$ and number $(p<0.0018)$ of processes when compared with processes of explants cultured in the nonsupplemented maintenance growth media (Figs. 2-6).

\section{Treatment with NT-3 plus the MEK inhibitor} U0126

Coincubation with the MEK inhibitor U0126 and NT3 resulted in a dose-dependent decrease in SG neurite length as U0126 concentration increased when compared with that for the explants treated with NT-3 alone. The length of $\mathrm{SG}$ processes observed on explants cultured in the NT-3- and U0126-supplemented media was significantly lower $(p<0.006)$ than that of explants treated with NT-3 alone at U0126 concentrations of $100 \mathrm{nM}$ and higher. Coincubation with NT-3 and a U0126 concentration of $1000 \mathrm{nM}$ also resulted in a significant $(p<0.002)$ decrease of the process length when compared with that of explants grown without NT-3 or U0126.

Coincubation with the MEK inhibitor U0126 and NT-3 also resulted in a dose-dependent decrease in SG neurite number with an increase in U0126 concentration when compared with that of explants treated with NT-3 alone. The number of SG processes observed in SG explants cultured in the U0126- and NT-3-supplemented media was significantly $(p<0.05)$ lower than the NT-3-treated cultures starting at $10 \mathrm{nM}$, the lowest 

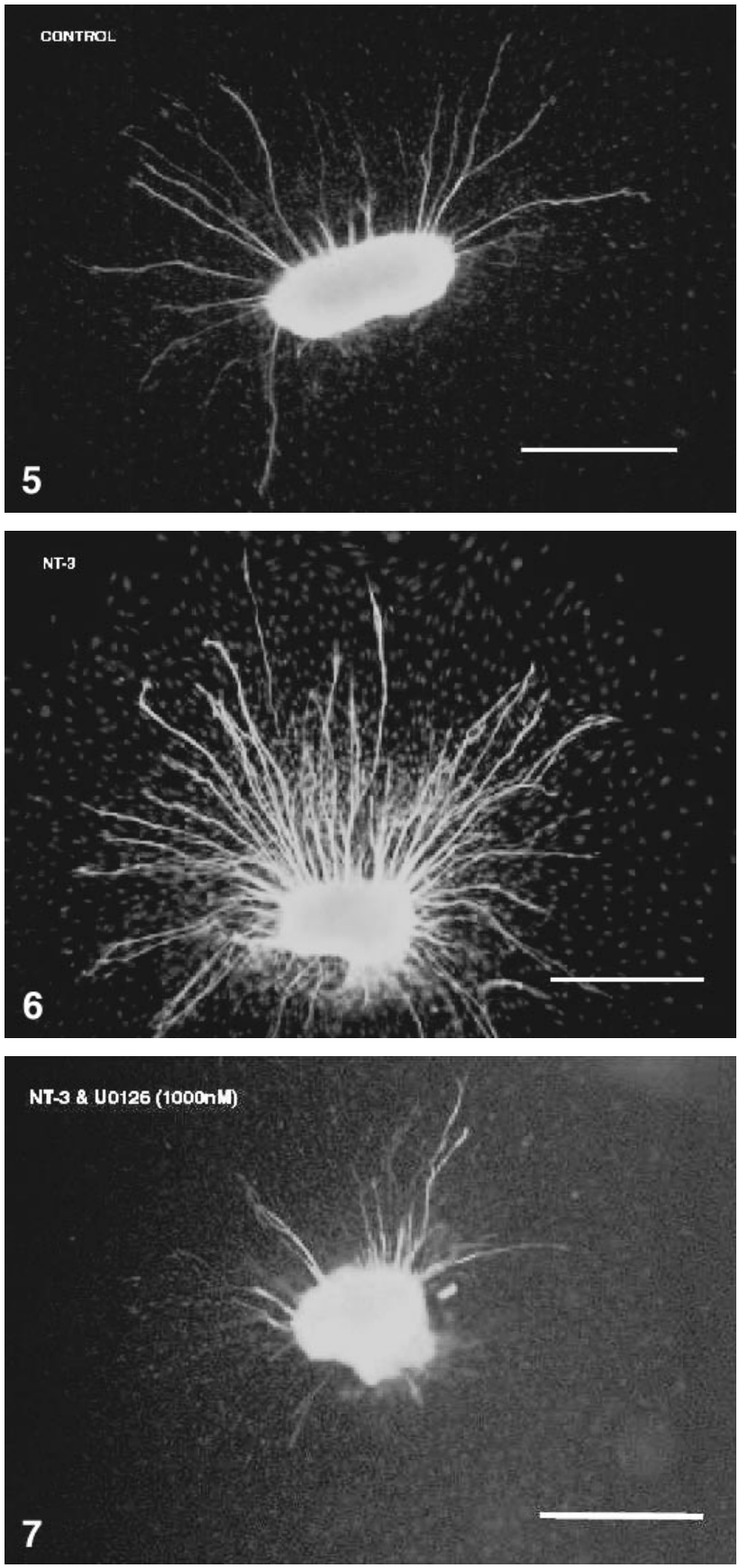

FIG. 5. Typical SG explant grown without NT-3 or inhibitors; scale bar $=250 \mu \mathrm{m}$.

FIG. 6. Typical SG explant treated with NT-3 (25 ng/mL); scale bar $=250 \mu \mathrm{m}$. Compared with control explants, the length and number of neurites are increased.

FIG. 7. Typical SG explant treated with NT-3 $(25 \mathrm{ng} / \mathrm{mL})$ and the MEK inhibitor U0126 (1000 nM); scale bar $=250 \mu \mathrm{m}$. NT-3-induced increase in neurite number are abolished, while neurite length is reduced below that of untreated control explants.

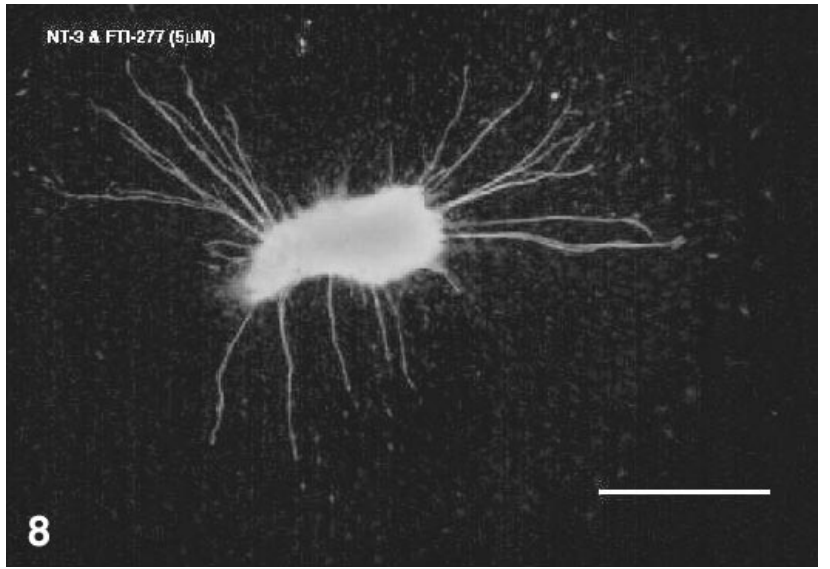

NT.3 2 FII.277 (10,M)

9

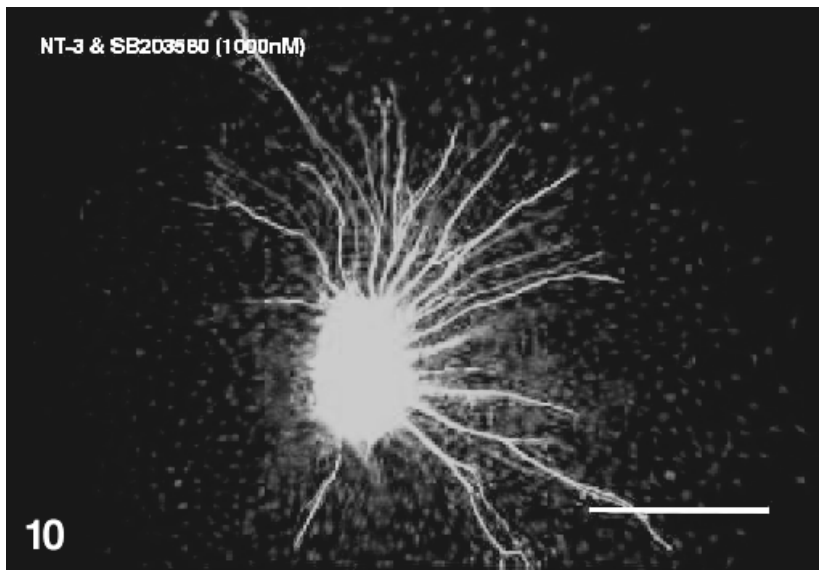

FIG. 8. Typical SG explant treated with NT-3 $(25 \mathrm{ng} / \mathrm{mL})$ and the Ras inhibitor FTI-277 $(5 \mu \mathrm{M})$; scale bar $=250 \mu \mathrm{m}$. NT-3-induced increase in neurite length and number are abolished.

FIG. 9. Typical SG explant treated with NT-3 $(25 \mathrm{ng} / \mathrm{ml})$ and the Ras inhibitor FTI-277 $(10 \mu \mathrm{M})$; scale bar $=250 \mu \mathrm{m}$. While the NT-3-induced increase in neurite length is reduced, the number of neurites remains higher than in controls.

FIG. 10. Typical SG explant treated with NT-3 $(25 \mathrm{ng} / \mathrm{mL})$ and the p38 inhibitor SB203580 (1000 nM); scale bar $=250 \mu \mathrm{m}$. The NT3 -induced increases in neurite length and number are unaffected. 
U0126 concentration included in this study (Figs. 2, $5-7)$

Treatment with NT-3 plus the Ras inhibitor FTI-277

When cultured in the Ras inhibitor FTI-277- and NT$3(25 \mathrm{ng} / \mathrm{ml})$-supplemented media, the neurite length of the experimental SG explants decreased in a dosedependent manner with an increase in FTI-277 concentration. Significant $(p<0.006)$ differences when compared with NT-3 alone were achieved at FTI concentrations of $2 \mu \mathrm{M}$ and higher. Interestingly, after coincubation with NT-3 and an FTI-277 concentration of $10 \mu \mathrm{M}$, process length was also significantly shorter $(p<0.023)$ compared with the nontreated control explants.

The number of neurites extending from SG explants cultured in the FTI-277 plus NT-3 showed a significant dose-dependent decrease in SG process number from $0.5 \mu \mathrm{M}(p<0.04)$ to $5 \mu \mathrm{M}(p<0.001)$ FTI-277. However at an FTI-277 concentration of 10 $\mu \mathrm{M}$, no significant $(p>0.12)$ difference from NT-3 treatment alone was observed (Figs. 3, 6, 8, 9).

Treatment with NT-3 plus the p38 inhibitor SB203580

Incubation in SB203580- and NT-3 (25ng/ml)-supplemented media had no significant effect on NT-3-mediated stimulation of neurite growth, in terms of either length $(p>0.06)$ or number $(p>0.12)$, at any concentration (Figs. 4, 6, 10)

\section{Control experiments}

Treatment with DMSO. The inhibitors used in the experiments included in this study were maintained in DMSO. Incubation of explants with $0.1 \%$ DMSO, the highest dose of this penetrant used in this study, resulted in no significant difference in terms of length $(p>0.5)$ and number $(p>0.5)$ of neurites when compared with control explants maintained in media alone (Table 1). Coincubation with NT-3 and 0.1\% DMSO resulted in no significant difference in terms of length $(p>0.5)$ and number $(p>0.5)$ of neurites when compared with that of explants grown in media supplemented only with NT-3 (Table 1). The data suggest that DMSO did not influence the results of the inhibitor experiments.

Treatment with the MEK inhibitor U0126 without NT-3. When cultured in media supplemented with the MEK inhibitor U0126 without NT-3, neurite length of the SG explants decreased significantly $(p<0.02)$ compared with that of explants grown in unsupplemented media

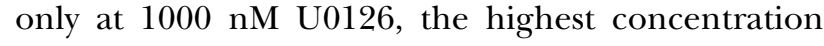

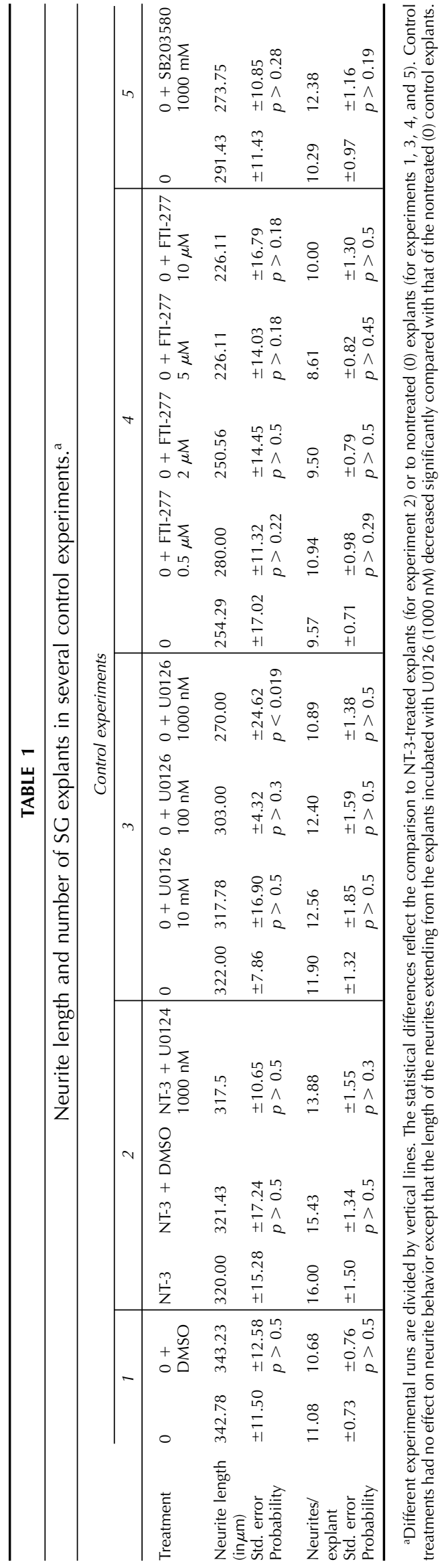


utilized in this study, but not at 10 or $100 \mathrm{nM}$. The number of neurites was not influenced in a significant manner $(p>0.5)$ compared with that of explants grown in unsupplemented media, at any dosage used (Table 1).

Treatment with NT-3 plus U0124. Explants cultured with NT-3 and $1000 \mathrm{nM} \mathrm{U0124} \mathrm{(a} \mathrm{negative} \mathrm{control}$ for the MEK inhibitor U0126) showed no significant difference when compared with NT-3-treated explants in terms of length $(p>0.5)$ or number $(p>0.3)$ (Table 1).

Treatment with the Ras inhibitor FTI-277 without NT-3. Incubation of SG explants cultured in unsupplemented media and treated with the Ras inhibitor FTI277 did not result in a significant difference in length $(p>0.18)$ or neurite number $(p>0.29)$ when compared with those of nontreated explants at any dosage investigated in this study (Table 1).

Treatment with the p38 inhibitor SB203580 without NT3. Incubation of SG explants grown in media supplemented with the p38 inhibitor SB203580 (1000 nM) did not influence SG neurite length $(p>0.28)$ or number $(p>0.19)$ when compared with those of nontreated explants (Table 1).

Treatment with trypan blue. After three days in culture, neurites extending from control SG explants as well as from the explants treated with the highest dosages of all inhibitors used in this study were unstained by trypan blue (data not shown) indicating that the levels employed were not toxic to the processes from the explants.

\section{DISCUSSION}

The observed effects of NT-3 support previous findings that this neurotrophin enhances the growth of SG neurites. The increase in the length of SG neuronal processes observed after coincubation with $25 \mathrm{ng} / \mathrm{mL}$ NT-3 and the fact that treatment with NT-3 resulted in a significant increase in the number of processes are consistent with observations of previous investigators (e.g., Pirvola et al. 1992; Staecker et al. 1996; Malgrange et al. 1996).

Neurite outgrowth from ganglion explants is a means of identifying robust neurotropic activity. Measuring the length of the extending processes is commonly applied, but evaluation of the numerical response can be difficult to quantify and measurement of neurite numbers can be influenced by the method applied. Neuronal outgrowth has been assessed by publishing images of ganglion explants (e.g., Pirvola et al. 1992) or by rating explants qualitatively (e.g., Lefebvre et al. 1991; Ebendal 1989). Image analysis to measure the area of the outgrowing neurites (e.g., Bisland et al. 1999) is quick but combines both process number and length in the measure. More quantitative techniques include hand counting of individial neurites (e.g., Liu et al. 1998; Dazert et al. 1998), the method utilized here.

In the present study the number of neurites was measured by counting the highest number of processes extending from the ganglion quarter with maximum neuronal outgrowth. A change in the density of extending SG neurites observed with this technique may be a result of several events. The additional processes could be caused by the promotion of SG neuron survival as shown in several previous studies evaluating the effect of NT-3 on SG neurons (e.g., Staecker et al. 1996; Malgrange et al. 1996). While we did not observe dying neurites using trypan blue, there may have been dying cell bodies within the explants that we did not visualize. Since the SG cells studied are postmitotic, differentiated neurons, an increase in neurite number through the induction of cell division seems unlikely. Another possibility is the induction of additional neurites from neurons in the explant. A higher number of processes could also be a result of the promotion of neurite branching, defasciculation, or the debundling of normally bundled fibers. We often noted defasciculation or debundling in our explants as a decrease in the width of neurite fascicles as fibers exit the bundle (Fig. 5). However, it is not possible to distinguish conclusively between debundling, defasciculation, and branching using light microscopy. NT-3 has been shown to enhance neurite branching in embryonic rat hippocampal cells (Morfini et al. 1994) but had no effect on neurite branching frequency of neuronal tube cells of E20 Xenopus laevis (McCaig et al. 2000). When neurite number increased because of NT-3 (Figs. 5 and 6), there were more neurites/neurite bundles even at the explant border. This suggests either the induction of more neurites from neurons in the explant or increased survival of neurons within the explant, consistent with many studies documenting a survival effect of this neurotrophin (Farinas et al. 1994; Malgrange et al. 1996; Staecker et al. 1996).

It should be noted that we could not distinguish between peripheral and central processes of SG neurons with the methods used in this study. If both dendritic and axonal neurites were present, they appeared to respond similarly to the substances used, as the growth of neurites was homogeneous in each condition. However, it is also possible that only one type of neurite exited the explants.

In the first part of this study, the activation of the ERK pathway by MEK was interrupted by U0126, a noncompetitive inhibitor that has been shown to specifically suppress the enzymatic activity of MEK and the successive phosphorylation of ERK, at the concentrations used in this study (DeSilva et al. 1998). Obviously, the role of the various intracellular pathways can 
be evaluated only if inhibitors that selectively suppress signaling through specific enzymes/pathways are obtainable. The inhibiting properties of U0126 have been shown to be selective for MEK-1 and -2, without affecting other enzymes such as Raf, JNK, MKK3, MKK6, and p38. The inhibiting effects of U0126 are mediated through binding to free MEK, MEK-ERK, and MEK-ATP complexes (Favata et al. 1998; DeSilva et al. 1998).

Coincubation of SG explants with U0126 and NT3 lead to a dose-dependent decrease of the length and number of the neuronal processes compared with those of the NT-3-stimulated cultures. Since U0124 had no effect, the results are specific to the inhibiting activity of U0126. The length of the processes observed at $1000 \mathrm{nM}$ U0126 was significantly shorter than the length of the neurites of NT-3-stimulated explants but also significantly shorter than those of the nonstimulated control explants. This finding and the observation that the highest concentration of MEK also reduced the neurite length on explants grown without NT-3 suggest that strong inhibition of MEK may suppress activities of additional factors besides NT-3. These could include the extracellular matrix molecules (Perron and Bixby 1999), the ingredients of the primary fetal-bovine-serum-supplemented media if they remained bound to the explants or extracellular matrix, or factors secreted by Schwann cells or fibroblasts. However, the results observed at 10 and $100 \mathrm{nM}$ were specific to NT-3.

The effects of the MEK inhibitor U0126 on NT3-stimulated SG process growth are consistent with findings of inhibition of neurotrophin effects in the rat visual cortex neurons (Pizzorusso et al. 2000) and mouse cerebellar granule neurons (Bulleit and Hsieh 2000) by U0126. They also conform with the inhibition of the neurotrophic effect of epidermal growth factor on cultured rat hippocampal neurons (Abe and Saito 2000a) and of basic fibroblast growth factor on cultured rat cortical neurons (Abe and Saito 2000b).

The results of the first part of this study, therefore, suggest that the signaling pathway for NT-3-stimulated SG neurite growth is dependent on MEK activation. MEK can be activated by Raf-1 through Ras-GTP, but it has also been shown that neurotrophin-mediated signaling through MEK is mediated by B-Raf through Rap-1-GTP, independent of Ras, in PC12 cells (York et al. 1998). To investigate whether the effects of NT3 on SG neurons are transmitted in a Ras-dependent manner, the activity of Ras was blocked in the second part of the study.

Ras is produced as a biologically inactive precursor molecule that is converted to its active state by the mobilization of Ras GDP/GTP exchange factors to the cell membrane, causing the release of GDP and its replacement by GTP. After activation, interactions with cell membrane lipids are crucial for the cellular activity of Ras. Farnesyl-transferase (FTase) anchors Ras to the cell membrane by farnesylation (Casey and Seabra 1996). When not anchored to the cell membrane, cytoplasmatic Ras in its GTP-bound form binds to various protein kinases to form inactive complexes. These complexes result in disruption of the Ras-specific activation of MAP kinase. The farnesylation of Ras can be prevented by the FTase inhibitor (FTI)-277, a peptidomimetic inhibitor of the FTase. Although the noncell-permeable form of FTI-277, FTI-276, has been shown to inhibit geranylgeranyltransferase at high concentrations, FTI-277 is considered a selective inhibitor of the FTase, as the inhibition of geranylgeranylated Rap-1A by FTI-277 does not occur at a concentration lower than $10 \mu \mathrm{M}$ (Lerner et al. 1995).

In the present study, treatment of NT-3-stimulated SG neurons with the Ras inhibitor FTI-277 leads to a concentration-dependent significant decrease of the length of the extending processes, while the neurite length of non-NT-3-treated control explants was not significantly influenced by FTI-277. This suggests that the signaling pathway for NT-3-stimulated neurite growth of SG neurons is dependent on Ras activation and can be blocked by inhibiting Ras farnesylation. At the highest dosage of FTI-277, NT-3-treated explants showed significant lower neurite length than control (non-NT-3-treated) explants. In contrast, $10 \mu \mathrm{M}$ FTI277 did not reduce neurite length of non-NT-3-treated explants. This difference suggests the possibility that NT-3 has a complex effect upon SG neurite length, including both Ras-dependent stimulatory influences and suppressive influences that are Ras-independent. Unmasking of such suppression by Ras inhibitors is consistent with our observations. The inhibition of Ras also resulted in a reduction of the number of neurites extending from the NT-3-treated explants (but again not from the non NT-3-treated control explants). This decrease in NT-3-stimulated neurite number was seen in a concentration-dependent manner from 0.5 to 5 $\mu \mathrm{M}$ but not at $10 \mu \mathrm{M}$. The loss of inhibition at 10 $\mu \mathrm{M}$ could reflect receptor upregulation (Raffioni and Bradshaw 1995) but may also be related to the alternate activities of the inhibitor. At low concentrations, FTI-277 has been shown to inhibit H-Ras (IC50 = $0.1 \mu \mathrm{M})$. Only at much higher concentrations does it suppress K-Ras (IC50 = $10 \mu \mathrm{M}$ ) (Lerner et al. 1995). To date, the distribution of the four isoforms of Ras (H-, N-, KA-, and KB-Ras) that have been described in mammalian cells has not been investigated in the inner ear, and, to our knowledge, no additional pharmacological tools with which to selectively investigate the individual Ras isoforms are available. However the increase in neurite numbers observed at this dosage could reflect different roles of the various Ras isoforms. 
Our results investigating the effect of FTI-277 are consistent with earlier observations which have shown neurite outgrowth induced by nerve growth factor in PC12 cells to be mediated by Ras (Hagag et al. 1986; Lange-Carter and Johnson 1994) and that there is selective reduction of neural cell adhesion moleculestimulated neurite outgrowth after the inhibition of Ras in rat cerebellar neuron cultures (Schmid et al. 1999). Together with the results of the first experiment, the results suggest that the effects of NT-3 on neurite growth of SG neurons occurs primarily via the Ras/MEK/ERK pathway.

Although the p38 MAPK pathway, the most recently identified group of MAPK family enzymes, has not been investigated as intensely as the ERK pathway, four isoforms of p38 ( $\alpha, \beta, \delta$ and $\gamma$ ) have been described (Hale et al. 1999). Cellular stress, such as inflammatory cytokines, endotoxins, and osmotic stress have been shown to activate this cascade (Freshney et al. 1994; Han et al. 1994; Lee et al. 1994). The p38 enzyme is activated through dual phosphorylation by MKK3 and MKK6 (Raingeaud et al. 1995), which in turn leads to the translocation of p38 to the nucleus, phosphorylating AF-2. Alternative downstream targets of p38 include MAPKAPK-2 as well as various transcription factors (Wang and Ron 1997; Han et al. 1997). The activation of p38 has been shown to be involved in cell proliferation and migration, as well as the promotion of cell death (Ono and Han 2000). Other groups have shown p38 activation after the stimulation of cerebellar granule cells (Morooka and Nishida 1998) and hippocampus cells (Blanquet 2000) by brain-derived neurotrophic factor.

When SG cells were coincubated with NT-3 and the p38 inhibitor SB203580 in the third part of this study, no significant changes in SG neurite length or number were observed at any of the concentrations investigated. SB203580 has been demonstrated to specifically inhibit the activation of the $\alpha$ and $\beta$ but not the $\delta$ and $\gamma$ p38 isoforms (Goedert et al. 1997), suggesting that at least the $\alpha$ and $\beta$ isoforms of p38 do not contribute to NT-3-stimulated increases in length and/or number of neurites from SG neurons. The results of the present study are consistent with the observations that neurite outgrowth from embryonic chick retinal neurons induced by basic fibroblast growth factor, laminin, or $\mathrm{N}$-caderin can be inhibited by ERK but not p38 inhibitors (Perron and Bixby 1999).

Neurite length and number generally showed similar responses to the treatment used in this investigation. However, there were significant differences. The highest dose of U0126 decreased neurite length but not number in non-NT-3-stimulated explants. The highest dose of FTI-277 significantly reduced NT-3stimulated increases in neurite length but not number.
These differences suggest that length and number of neurites are differentially regulated in SG explants.

\section{ACKNOWLEDGMENTS}

Sincere thanks are due to Dr. R. Lieber for assistance with statistical evaluation. Research supported by funds from the Deutsche Forschungsgemeinschaft (DFG) grant Al 526/11, NIH/NIDCD grant DC00139 and the Research Service of the Veteran Administration.

\section{REFERENCES}

ABE K, SAITO H. Neurotrophic effect of basic fibroblast growth factor is mediated by the $\mathrm{p} 42 / \mathrm{p} 44$ mitogen-activated protein kinase cascade in cultured rat cortical neurons Brain Res. Dev. Brain Res. 122:81-85, 2000a.

ABE K, SAITo H. The mitogen-activated protein kinase cascade mediates neurotrophic effect of epidermal growth factor in cultured rat hippocampal neurons Neurosci. Lett. 282:89-92, 2000b.

Bilsland J, Rigby M, Young L, Harper S. A rapid method for semi-quantitative analysis of neurite outgrowth from chick DRG explants using image analysis J. Neurosci. Meth. 92:75-85, 1999.

BLANQUET PR. Identification of two persistently activated neurotrophin-regulated pathways in rat hippocampus Neuroscience 95:705-719, 2000

Boulton TG, Nye SH, Robbins DJ, Ip NY, RADZIEjEWSka E, Morgenbesser SD, Depinho RA, Panayotatos N, Cobb MH, YancoPOULOS GD. ERKs: a family of protein-serine/threonine kinases that are activated and tyrosine phosphorylated in response to insulin and NGF Cell 65:663-675, 1991.

Bulleit RF, HsIEH T. MEK inhibitors block BDNF-dependent and -independent expression of GABA(A) receptor subunit mRNAs in cultured mouse cerebellar granule neurons Brain Res. Dev. Brain Res. 119:1-10, 2000.

Casey PJ, SEabra MC. Protein prenyltransferases J. Biol. Chem. 271:5289-5292, 1996.

CHAO MV. Neurotrophin receptors: a window into neuronal differentiation Neuron 9:583-593, 1992.

Crews CM, ERIKSON RL. Purification of a murine protein-tyrosine/ threonine kinase that phosphorylates and activates the Erk-1 gene product: relationship to the fission yeast byr1 gene product Proc. Natl. Acad. Sci. USA 89:8205-8209, 1992.

Dazert S, Kim D, Luo L, Aletsee C, Garfunkel S, Maciag T, BAIRD A, RYAN AF. Focal delivery of fibroblast growth factor-1 by transfected cells induces spiral ganglion neurite targeting in vitro J. Cell Physiol. 177:123-129, 1998.

DeSilva DR, Jones EA, Favata MF, Jaffee BD, Magolda RL, TRZASKOS JM, SCHERLE PA. Inhibition of mitogen-activated protein kinase kinase blocks $\mathrm{T}$ cell proliferation but does not induce or prevent anergy J. Immunol. 160:4175-4181, 1998.

EBENDAL T. Use of collagen gels to bioassay nerve growth factor activity. In: Rush RA, (ed) Nerve growth Factors Wiley Bath, England, 1989, 81-83.

FARINAS I, JONES KR, BACKus C, WANG XY, REICHARDT LF. Severe sensory and sympathetic deficits in mice lacking neurotrophin-3 Nature 369:658-661, 1994.

Favata MF, Horiuchi KY, Manos EJ, Daulerio AJ, Stradley DA, FeEser WS, VAN dYK DE, PitTs WJ, EARL RA, HobBs F, Copeland RA, Magolda RL, Scherle PA, TrZaskos JM. Identification of a novel inhibitor of mitogen-activated protein kinase kinase J. Biol. Chem. 273:18623-18632, 1998. 
Freshney NW, RaWlinson L, Guesdon F, Jones E, Cowley S, Hsuan J, SAKLATVAla J. Interleukin-1 activates a novel protein kinase cascade that results in the phosphorylation of Hsp27 Cell 78:10391049, 1994.

Goedert M, Cuenda A, Craxton M, Jakes R, Cohen P. Activation of the novel stress-activated protein kinase SAPK4 by cytokines and cellular stresses is mediated by SKK3 (MKK6); comparison of its substrate specificity with that of other SAP kinases EMBO J. 16:3563-3571, 1997.

Hagag N, Halegoua S, Viola M. Inhibition of growth factorinduced differentiation of PC12 cells by microinjection of antibody to ras p21 Nature 319:680-682, 1986.

Hale KK, Trollinger D, Rihanek M, Manthey CL. Differential expression and activation of p38 mitogen-activated protein kinase alpha, beta, gamma, and delta in inflammatory cell lineages J. Immunol. 162:4246-4252, 1999.

Han J, Jiang Y, Li Z, Kravchenko VV, Ulevitch RJ. Activation of the transcription factor MEF2C by the MAP kinase p38 in inflammation Nature 386:296-299, 1997.

Han J, LeE JD, Bibbs L, Ulevitch RJ. A MAP kinase targeted by endotoxin and hyperosmolarity in mammalian cells Science 265:808-811, 1994

Iwasaki S, Iguchi M, Watanabe K, Hoshino R, Tsujimoto M, KoHNO M. Specific activation of the p38 mitogen-activated protein kinase signaling pathway and induction of neurite outgrowth in PC12 cells by bone morphogenetic protein-2 J. Biol. Chem. 274:26503-26510, 1999.

KAPLAN DR, MiLLER FD. Neurotrophin signal transduction in the nervous system Curr. Opin. Neurobiol. 10:381-391, 2000.

Kim D, Aletsee C, Dazert D, Ryan AF. Fibronectin enhances spiral ganglion neurite outgrowth in vitro. 2000, Submitted.

Kyriakis JM, Banerjee P, Nikolakaki E, Dai T, Rubie EA, Ahmad MF, Avruch J, WoOdgett JR. The stress-activated protein kinase subfamily of c-Jun kinases Nature 369:156-160, 1994.

LAMBALle F, KLEIN R, BARBACID M. trkC, a new member of the trk family of tyrosine protein kinases, is a receptor for neurotrophin3 Cell 66:967-979, 1991.

LANGE-CARTER CA, JOHNSON GL. Ras-dependent growth factor regulation of MEK kinase in PC12 cells Science 265:1458-1461, 1994.

LeE JC, Laydon JT, MCDonnell PC, Gallagher TF, Kumar S, Green D, McNulty D, Blumenthal MJ, Heys JR, Landvatter et al. SW. A protein kinase involved in the regulation of inflammatory cytokine biosynthesis Nature 372:739-746, 1994.

LefebVRe PP, VAN de Water TR, RePresa J, LiU W, BERnd P, Modlin S, Moonen G, Mayer MB. Temporal pattern of nerve growth factor (NGF) binding in vivo and the in vitro effects of NGF on cultures of developing auditory and vestibular neurons Acta Otolaryngol 111:304-311, 1991.

Lefebvre PP, Weber T, Rigo JM, Staecker H, Moonen G, Van de WATER TR. Peripheral and central target-derived trophic factor(s) effects on auditory neurons Hear. Res. 58:185-192, 1992.

Lerner EC, Qian Y, Blaskovich MA, Fossum RD, Vogt A, Sun J, Cox AD, Der CJ, Hamilton AD, Sebti SM. Ras CAAX peptidomimetic FTI-277 selectively blocks oncogenic Ras signaling by inducing cytoplasmic accumulation of inactive Ras-Raf complexes J. Biol. Chem. 270:26802-26806, 1995.

Liu HM, TAKagaki K, Schmid K. In vitronerve-growth-promoting activity of human plasma alpha 1-acid glycoprotein J. Neurosci. Res. 20:64-72, 1988.

Malgrange B, Lefebvre P, VAn de water TR, STAecker H, MoOnen G. Effects of neurotrophins on early auditory neurones in cell culture Neuroreport 7:913-917, 1996.
MARSHALL CJ. Specificity of receptor tyrosine kinase signaling: transient versus sustained extracellular signal-regulated kinase activation Cell 80:179-185, 1995.

McCaig CD, SANGSTer L, Stewart R. Neurotrophins enhance electric field-directed growth cone guidance and directed nerve branching Dev. Dyn. 217:299-308, 2000.

Merlio JP, ERnfors P, Jaber M, Persson H. Molecular cloning of rat trkC and distribution of cells expressing messenger RNAs for members of the trk family in the rat central nervous system Neuroscience 51:513-532, 1992.

Morfini G, Ditella MC, Feiguin F, Carri N, Caceres A. Neurotrophin-3 enhances neurite outgrowth in cultured hippocampal pyramidal neurons J. Neurosci. Res. 39:219-232, 1994.

MOROOKA T, Nishida E. Requirement of p38 mitogen-activated protein kinase for neuronal differentiation in PC12 cells J. Biol. Chem. 273:24285-24288, 1998.

ONO K, HAN J. The p38 signal transduction pathway: activation and function Cell Signal. 12:1-13, 2000.

PERron JC, Bixby JL. Distinct neurite outgrowth signaling pathways converge on ERK activation Mol. Cell. Neurosci. 13:362-378, 1999.

Pirvola U, Arumae U, Moshnyakov M, Palgi J, SaArma M, Ylikoski J. Coordinated expression and function of neurotrophins and their receptors in the rat inner ear during target innervation Hear. Res. 75:131-144, 1994.

Pirvola U, Ylikoski J, Palgi J, Lehtonen E, Arumae U, SaArma M. Brain-derived neurotrophic factor and neurotrophin 3 mRNAs in the peripheral target fields of developing inner ear ganglia Proc. Natl. Acad. Sci. USA 89:9915-9919, 1992.

Pizzorusso T, Ratto GM, Putignano E, Maffei L. Brain-derived neurotrophic factor causes cAMP response element-binding protein phosphorylation in absence of calcium increases in slices and cultured neurons from rat visual cortex J. Neurosci. 20:28092816, 2000.

RAFFioni S, BRADSHAW RA. Staurosporine causes epidermal growth factor to induce differentiation in PC12 cells via receptor upregulation J. Biol. Chem. 270:7568-7572, 1995.

Raingeaud J, Gupta S, Rogers JS, Dickens M, Han J, Ulevitch RJ, DAVIS RJ. Proinflammatory cytokines and environmental stress cause p38 mitogen-activated protein kinase activation by dual phosphorylation on tyrosine and threonine J. Biol. Chem. 270:7420, 1995.

Rouse J, Cohen P, Trigon S, Morange M, Alonso-Llamazares A, Zamanillo D, Hunt T, Nebreda AR. A novel kinase cascade triggered by stress and heat shock that stimulates MAPKAP kinase2 and phosphorylation of the small heat shock proteins Cell 78:1027-1037, 1994.

SCHMid RS, GrafF RD, Schaller MD, Chen S, Schachner M, HempERLY JJ, MANESS PF. NCAM stimulates the Ras-MAPK pathway and CREB phosphorylation in neuronal cells J. Neurobiol. 38:542558, 1999.

Staecker H, Kopke R, Malgrange B, Lefebvre P, Van de Water TR. NT-3 and/or BDNF therapy prevents loss of auditory neurons following loss of hair cells Neuroreport 7:889-894, 1996.

Sutter A, Riopelle RJ, Harris-Warrick RM, Shooter EM. Nerve growth factor receptors. Characterization of two distinct classes of binding sites on chick embryo sensory ganglia cells J. Biol. Chem. 254:5972-5982, 1979.

VAn DE WATER TR, Ruben RJ. Organ culture of the mammalian inner ear Acta Otolaryngol. 71:303-312, 1971.

WANG XZ, RON D. Stress-induced phosphorylation and activation of the transcription factor CHOP (GADD153) by p38 MAP kinase Science 272:1347-1349, 1996.

York RD, Yao H, Dillon T, Ellig CL, Eckert SP, McCleskey EW, STORK PJ. Rap1 mediates sustained MAP kinase activation induced by nerve growth factor Nature 392:622-626, 1998. 